\title{
Scientific Approaches in Screening the Analgesic property of Sida Cordata
}

Srinivasan $K^{1 *}$, Haja Sherief $S^{2}$, Duraisami $R^{3}$, Sivakumar $T^{1}$, Kiruthiga $\mathbf{N}^{1}$, Sengottuvelu $S^{2}$

${ }^{1}$ Department of Pharmaceutical Chemistry,

${ }^{2}$ Department of Pharmacology,

${ }^{3}$ Department of Pharmacognosy,

Nandha College of Pharmacy, Erode - 638052. Tamil Nadu.

\section{*Corresponding Author}

Dr. K. Srinivasan, M.Pharm., Ph.D.,

Professor, Department of Pharmaceutical Chemistry,

Nandha College of Pharmacy,

Erode - 638052 Tamil Nadu.

Email ID: sriudha@gmail.com 


\begin{abstract}
Pain is likely the most common symptomatic complaint in medicine; an understanding of its mechanism is critical to interpret it. Nociception refers to the detection of noxious stimuli by nociceptors, followed by transduction and transmission of the sensory nervous information from the periphery to the brain. Plants have played a unique holistic role for the provision of food, drugs, clothing, shelter, etc. Natural compounds have been extensively explored for new drug discoveries. Indeed, plants have been used as medicines for more than 5000 years, as a source of antibiotics, antineoplastic, analgesics, cardioprotective, among others. About $70-90 \%$ of the population in developing countries continue to use ancient medicines based on plant extracts. Sida cordata popularly known as "bala" is regarded as a valuable drug in the Ayurvedic System of Indian Medicine. In order to validate the ethnomedical claim of Sida cordata as pain reliever, a study was conducted to evaluate the analgesic activity of ethanolic extract of Sida cordata whole plant in laboratory animals. For centrally mediated analgesic activity, eddy's hot plate method was employed and Pentazocine was uses as reference control. For peripherally mediated analgesic activity, acetic acid induced writhing model was employed and Dicofenac was used as reference control. Sida cordata ethanolic extract was administered orally at the doses of 100 and 200 $\mathrm{mg} / \mathrm{kg}$. In eddy's hot plate method, both the doses of Sida cordata significantly increased the reaction time compare to vehicle control. In acetic acid induced writhing test, both the doses of Sida cordata significantly reduced the number of writhing compare to vehicle control. In both the models, the effect produced by Sida cordata was comparable to that of respective reference control. The results obtained suggest that the ethanolic extract of Sida cordata has showed marked analgesic activity in experimental animal models and this strappingly supports the ethnopharmacological applications of the plant for the target activity.
\end{abstract}

Key words: Sida cordata, Analgesic, Eddy's hot plate, Acetic acid, Writhing 


\section{Introduction}

For millennia, medicinal plants have been a valuable source of therapeutic agents, and still, many of today's drugs are plant-derived natural products or their derivatives (1). Natural products and especially medicinal plants have great importance for the development of new drugs used in human medicine. The plant kingdom has significantly contributed to the development of new drugs to be used in the treatment of various diseases (2). In addition, the pharmacological research of active ingredients of medicinal plants has provided important advances in the therapeutic management of many diseases, wherein several substances found in plants have been used as useful targets for pharmacological, physiological and biochemical studies (3). Inflammation is a basic mechanism in which the body responds to infection, irritation or other injury of the body cells and tissues, and the key feature being redness, warmth, swelling and pain (4). Sida cordata belongs to the family Malvaceae, is a small weed found throughout India, usually available on the roadsides and other waste places (5). The plant Sida cordata commonly known as Bhumibala, Nagabala in Sanskrit; Kurunthotti, Palampasi, Mayirmanikkam in Tamil and Bhuinii in Hindi. The plant can be easily recognized, and the entire plant is used in making medicine (6). This plant is widely distributed in India, Pakistan and other tropical countries (7). Sida cordata is highly reputed plant in ayurvedic system of medicine used as antibacterial, antitumor, antifungal, antiulcer, antitussive, anti-inflammatory, anti-malarial, anti-oxidant, analgesic, antidepressant, antihyperglycemic, hepatoprotective in ayurvedic system of medicine (8). In order to establish the analgesic activity of Sida cordata, current study has been selected, based on the ethno-pharmacological importance. 


\section{Materials and Methods}

\section{Plant material}

The plant Sida cordata belongs to the family Malvaceae was collected from Tirupati, India. The plant material was taxonomically identified, confirmed and authenticated by Dr. K. Madhava Chetty, Sri Venkateswara University, Tirupati and the voucher specimen (SVU/ 5321) deposited in the herbarium for future reference.

\section{Preparation of Extract}

The whole plant was dried under shade with occasional shifting and then crushed with a mechanical grinder and stored in an airtight container. The powdered root material was evenly packed in the Soxhlet apparatus and continuous hot extraction was carried out for $72 \mathrm{~h}$ using solvents like petroleum ether, chloroform, and ethanol successively. The solvent used were purified after each extraction. The extracts were filtered through whattman filter paper to remove the impurities, if any present, and concentrated by vacuum distillation. Then the concentrated extracts were placed in desiccators to remove the excess moisture. The dried extract was kept in airtight container and used for further studies.

\section{Preliminary Phytochemical Screening}

To identify the phytoconstituents, the extracts of Sida cordata were subjected to preliminary phytochemical screening for the presence of various secondary metabolites which was carried out using standard procedure $(9,10,11)$.

\section{Animals}

Swiss albino mice weighing between 18-20 g was used for the study. The animals were obtained from animal house of Kerala Veterinary and Animal Science University, Kerala, Mannuthy. On arrival, the animals were placed in the animal house of Nandha College of Pharmacy for acclimatization in a stainless cage with dried grass bedding. Animals were housed at a temperature of $24 \pm 2{ }^{\circ} \mathrm{C}$ and relative humidity of $30-70 \%$. A 12:12 light: dark cycle was followed. All animals were allowed free access to water and fed with standard commercial pelleted rat chaw Hindustan Lever Ltd, Mumbai). All the experimental procedures and protocols used in this study were reviewed by the Institutional Animal Ethics Committee 688/PO/Re/S/02/CPCSEA) and were in accordance with the guidelines of the IAEC. 


\section{Evaluation of Analgesic Activity}

\section{Eddy's Hot Plate Method}

Mice were divided into four groups each containing six animals. Group I animals served as a normal control and received 0.5\% CMC, Group II animals served as positive control, received Pentazocine 30mg/kg i.p.) while Group III and IV animals received the 100 and $200 \mathrm{mg} / \mathrm{kg}$ body weight of the Sida cordata extract. The hot plate temperature was kept at $55^{\circ} \pm 0.5^{\circ} \mathrm{C}$ and the cut off time was $15 \mathrm{~s}$. The parameter evaluated was the latency time for licking of legs and jumping responses after exposure on the hot plate surface. The increase in latency time in relation to control was taken as an index of analgesic activity (12). The basal reaction time in seconds was investigated at 30,60 and 120 min after treatment. Changes in reaction time were noted.

\section{Acetic acid induced writhing test in mice}

The peripheral analgesic activity of the extract was determined by the acetic acid induced writhing inhibition method (13). Mice were divided into four groups of six animals. Group I animals served as a normal control and received 0.5\%CMC, group II animals served as a positive control, received Diclofenac $10 \mathrm{mg} / \mathrm{kg}$, i.p.), while the group III and IV animals received 100 and $200 \mathrm{mg} / \mathrm{kg}$ b.w. of Sida cordata respectively through oral route. Acetic acid $1 \% \mathrm{v} / \mathrm{v}$ ) at a dose of $0.1 \mathrm{ml} / 10 \mathrm{~g}$ of body weight was administered intraperitoneally to all groups, $1 \mathrm{~h}$ after oral administration of test drugs. The number of writhing episodes were noted for $10 \mathrm{~min}$ and was compared with Diclofenac.

\section{Statistical Analysis}

The values were presented as mean \pm SEM. Data's were analyzed by one-way ANOVA followed by Dunnett's ' $t$ ' test and $\mathrm{P}$ value of 0.05 was considered as statistically significant. 


\section{Results}

\section{Phytochemical Screening}

The ethanolic extract of Sida cordata was subjected to phytochemical analysis and results were shown the presence of the Flavonoids, Tannins, Saponins, Sterols, Triterpenoids, Alkaloids and Glycosides.

\section{Analgesic activity}

\section{Eddy's Hot Plate}

Figure 1. Analgesic Activity of Sida cordata in Eddy's hot plate model

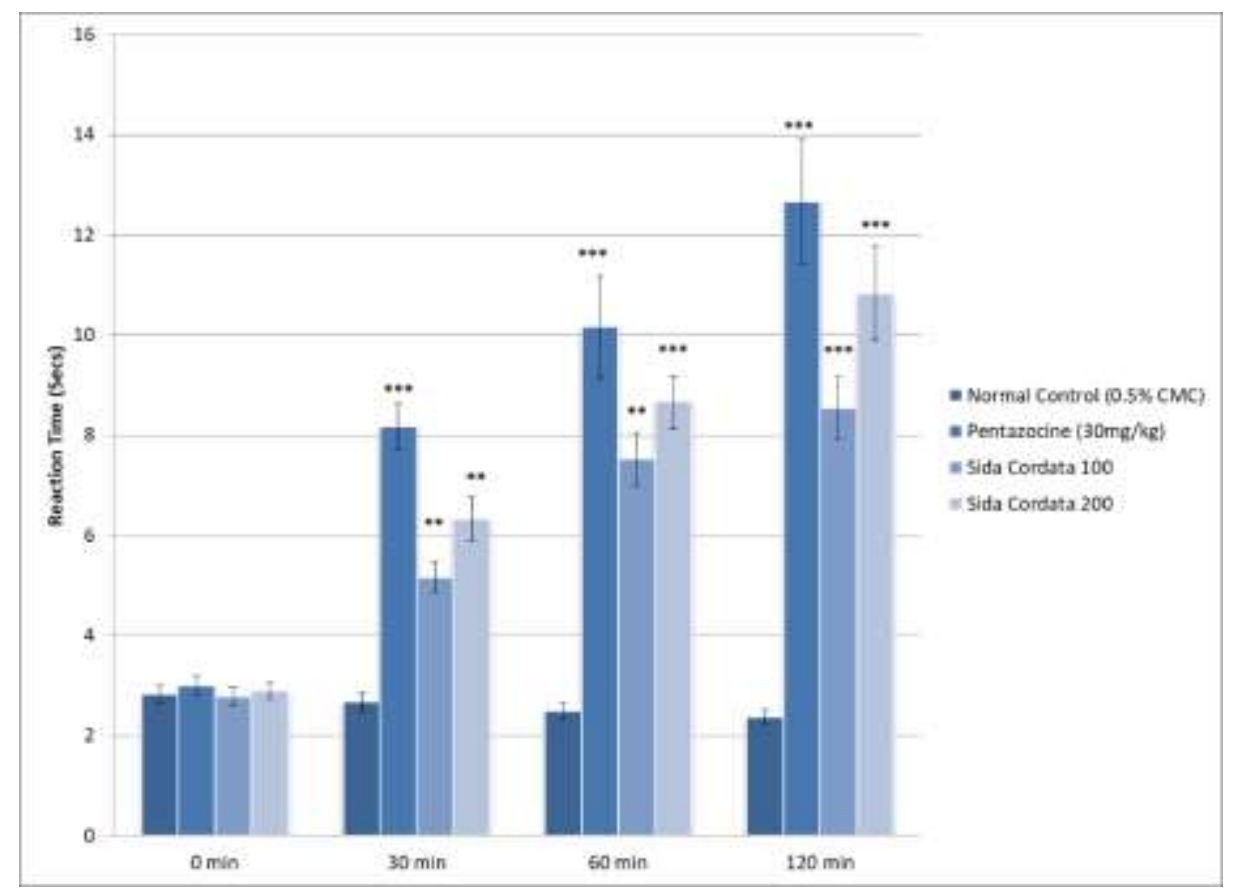

Values are in Mean \pm SEM $\mathrm{n}=6) ; * \mathrm{P}<0.05, * * \mathrm{P}<0.01$ and $* * * \mathrm{P}<0.001$ Vs Normal Control

The results of the analgesic activity of Sida Cordata using hot plate method are presented in Figure 1. There was no significant difference on the thermal stimulus in mice treated with the vehicle normal control throughout the whole time of the experiment. Pentazocine administration significantly increased response time of the animal to reach 12.67 secs at 120 minutes. Both the doses of Sida cordata significantly increased the reaction time compare to control. Observation of reaction time at 30 and 60 minutes showed significant $(\mathrm{P}<0.01)$ increase in reaction time of Sida cordata at the dose level of $100 \mathrm{mg} / \mathrm{kg}$ and more significantly $(\mathrm{P}<0.001)$ it enhances the reaction time at 120 minutes. Observation of 
reaction time at 30 minutes showed significant $(\mathrm{P}<0.01)$ increase in reaction time of Sida cordata at the dose level of $200 \mathrm{mg} / \mathrm{kg}$ and more significantly $(\mathrm{P}<0.001)$ it enhances the reaction time at 60 and 120 minutes.

\section{Acetic Acid Induced Writhing}

Figure 2. Analgesic Activity of Sida cordata in Acetic Acid Induced Writhing model

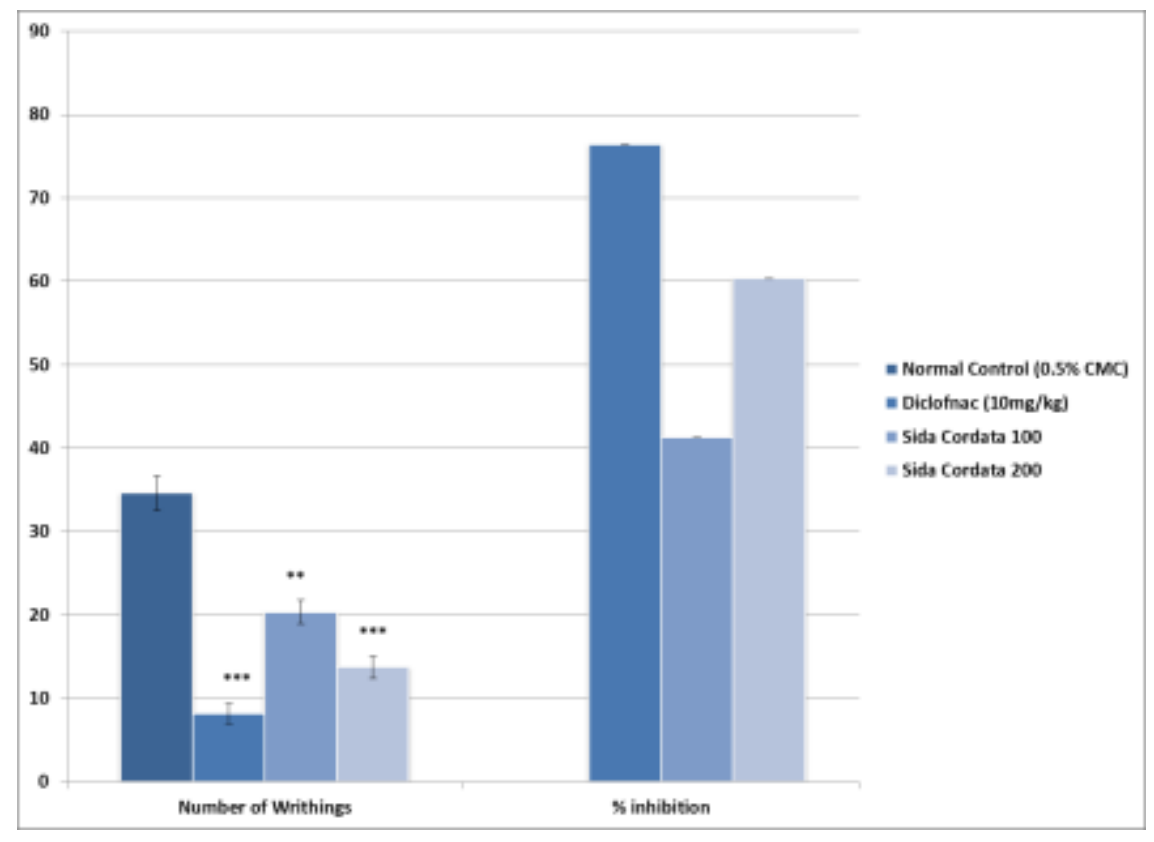

Values are in Mean \pm SEM $\mathrm{n}=6) ; * \mathrm{P}<0.05, * * \mathrm{P}<0.01$ and $* * * \mathrm{P}<0.001$ Vs Normal Control

The results of the analgesic activity of Sida Cordata using acetic acid induced writhing model are presented in Figure 1. Acetic acid is a noxious stimulant induce pain in peripheral region. In acetic acid control, the number of writhing's were 34.62 and the reference control diclofenac significantly $(\mathrm{P}<0.001)$ reduced the writhing response to 8.16 and the percentage inhibition was 76.43\%. Both the doses 100 and $200 \mathrm{mg} / \mathrm{kg}$ of Sida cordata significantly $(\mathrm{P}<0.01$ and $\mathrm{P}<0.001)$ reduced the writhing response to 20.32 and 13.72 respectively compare to normal control. The percentage inhibition of 100 and $200 \mathrm{mg} / \mathrm{kg}$ of Sida cordata was found to be $41.31 \%$ and $60.36 \%$ respectively. 


\section{Discussion}

The ethanolic extract of Sida cordata was evaluated for analgesic on centrally as well as peripherally using Eddy's hot plate and acetic acid induced writhing models respectively. The hot plate test is widely used to assess analgesic activity of drugs. This test does not directly measure the intensity of the noxious stimulus perceived by the animal, but also the animal's response to it and so may be affected non-analgesic drugs. Sedative and muscle relaxants may impair the ability to response and hence be wrongly considered to have analgesic activity. The validity of this method has been shown even in the presence of substantial impairment of motor performance. It is an established fact that any agent that causes a prolongation of the hot plate latency using this test must be acting centrally (14). The acetic acid-induced writhing test in mice is widely used to screen and study compounds for peripherally mediated analgesic activity. Intraperitoneal administration of acetic acid induces endogenous pain mediators, such as prostaglandins, histamine, serotonin 5-HT, bradykinin and substance $\mathrm{P}$ that sensitize pain nerve endings (14). The sensation of pain develops with the activation of nociceptor mediated by mechanical, thermal or chemical stimuli. Although several factors have been identified, enzymes phospholipase, cyclooxygenase, peroxidase and stimulation of sensory neurons spinal and supraspinal have been implicated as major contributing factors in the generation of pain. In the management of pain, several improved analgesic agents have been developed, but there is considerable opportunity regarding innovation of pain reliever (15). The Pain sensation in acetic acid induced writhing response is demonstrated by triggering localized inflammatory response due to release of free arachidonic acid from tissue phospholipids via cyclo-oxygenase COX), and prostaglandin specifically PGE2 and PGF2 biosynthesis, the level of lipoxygenase products may also increase in peritoneal fluids. These prostaglandin and lipoxygenase products cause inflammation and pain. Inhibition of writhing indicates analgesic effects of a substance mediated by inhibition of prostaglandin synthesis, a peripheral mechanism of pain inhibition (15). The acetic acid induced writhing response is a sensitive procedure to evaluate peripherally acting analgesics (16). Significant decrease in number of writhes and increase in tail flick latency was observed in acetic acid induced writhing and tail flick test, respectively. A good central and peripheral analgesic activity was showed by hot plate and writhing tests. Many plants containing flavonoids have been shown to have diuretic, laxative, antispasmodic, anti-hypertensive, and anti-inflammatory actions. Flavonoids and saponins are well known for their ability to inhibit pain perception as well as anti-inflammatory properties 
due to their inhibitory effects on enzymes involved in the production of the chemical mediator of inflammation. The ability of flavonoids to inhibit eicosanoid biosynthesis has been documented. Eicosanoids, such as prostaglandins, are involved in various immunological responses and are the end products of the cyclooxygenase and lipoxygenase pathways. Further, flavonoids can inhibit neutrophils degranulation and thereby decrease the release of arachidonic acid (17). Due to this, the flavonoids present in the Sida cordata extract might be responsible for the significant analgesic activity on experimental animals.

\section{Conclusion}

From the result, it was concluded that, the ethanolic extract of Sida Cordata whole plant confirmed significant analgesic activity and may be acting through peripheral pain mechanism via influencing the prostaglandin pathway, as well as centrally mediated opioid receptors. Yet, more work is required in the isolation and characterization of the bioactive compounds from Sida cordata and further studies to determine the exact mechanism of action. 


\section{References}

1. Kinghorn AD, Pan L, Fletcher JN, Chai H. The relevance of higher plants in lead compound discovery programs. J Nat Prod 2011; 74): 1539-1555.

2. Newman DJ, Cragg GM. Natural products as sources of new drugs over the 30 years from 1981 to 2010. J Nat Prod 2012; 75: 311-335.

3. Rates SM. Plants as source of drugs. Toxicon2001; 39: 603-613.

4. Oyedapo OA, Adewunmi CO, Iwalewa EO, Makanju VO. J Biol Sci 2008; 81): 131136.

5. Warrier PK, Nambiar VPK, Raman Katty C, Vasudevan Nair R. Indian Medicinal Plants, vol-5, 129-131.

6. Agasthiar Pannendayiram Ennum Perunool Kaviyam, $2^{\text {nd }}$ Edition, Thamarai Noolagam, Chennai, India 1995; 322.

7. Gnanasekaran D, Umamaheswara Reddy C, Jaiprakash B, Narayanan N, Hannah Elizabeth S, Ravi Kiran Y. Adaptogenic activity of a Siddha medicinal plant: Sida cordata. Int J Pharm Biomed Res 2012; 31): 7-11.

8. Kokate CK. Practical Pharmacognosy. $1^{\text {st }}$ Edition. New Delhi: Vallabh Prakashan; 1994.

9. Harborne JB. Phytochemical Methods: A Guide to Modern Techniques of Plant Analysis. Chapman and Hall, London; 2005; 182-189.

10. Persinos GJ, Quimby MW. Nigerian Plants III. Phytochemical Screening for Alkaloids, Saponins and Tannins. J Pharm Sci 1967; 56 2): 1512.

11. Peach K. Modern Methods of Plant Analysis, vol-4. Springer-Verlag 1955.

12. Eddy NB, Leimbach DJ. Synthetic analgesics. II. Dithienylbutenyl and dithienylbutilamines. J Pharmacol Exp Ther 1953; 107: 385.

13. Whittle BA. The use of changes in capillary permeability in mice to distinguish between narcotic and non-norcotic analgesics. Br J Pharmacol 1964; 22): 246-253.

14. Ali MS, Nasrin M, Dash PR. Evaluation of analgesic and CNS depressant activities of Grewia paniculatain Swiss albino Mice. Am J Food Nutr 2015; 31): 21-27.

15. Badrul A, Fahima A, Nahida P, Rashna SP, Sharmin A, Jesmin C, et al. Antioxidant, analgesic and anti-inflammatory activities of the methanolic extract of Piper betle leaves. AJP 2013; 32): 112-125.

16. Uddin MJ, Rahman MM, Mamun MA, Sadik G. Vanda roxburghii: an experimental evaluation of antinociceptive properties of a traditional epiphytic medicinal orchid in animal models. BMC Complement Altern Med 2015; 15: 305. 
17. Kaushik D, Kumar A, Kaushik P, Rana AC. Analgesic and anti-inflammatory activity of Pinus roxburghii Sarg. Adv Pharmacol Sci 2012; 2012: 1-6. 